\title{
Experimental Study of Soot Volume Fraction Applied in Laminar Diffusion Flames
}

\author{
N. R. Caetano, F. M. Pereira, H. A. Vielmo, F. T. van der Lann \\ Federal University of Rio Grande do Sul, DEMEC-UFRGS, Porto Alegre, Brazil \\ Email: nattan@ufrgs.br
}

Received August 8, 2013; revised September 17, 2013; accepted September 30, 2013

Copyright (C) 2013 N. R. Caetano et al. This is an open access article distributed under the Creative Commons Attribution License, which permits unrestricted use, distribution, and reproduction in any medium, provided the original work is properly cited.

\begin{abstract}
The soot emission has been the focus of many studies due to applications in industry and the prejudicial effects caused to the environment. The presence of soot is important to the heat transfer in boilers and combustion chambers, contributing significantly to efficiency increases. In controversy, the inhaled soot may cause respiratory system damage and even cancer. Another important point is the contribution to the greenhouse effect. Therefore, the aim of this work is to analyse the soot emission in laminar diffusion flames produced from commercial fuels stabilized on a burner representative of industrial applications. Methane, vehicular natural gas and liquid petroleum gas are considered as fuels. An experimental setup was constructed to implement the technique of laser light extinction and laser-induced incandescence. These non-intrusive techniques provide instant information, in real time, about soot volume fraction. The measurements were calibrated and validated using methods and results of studies available in the literature, and also the uncertainty is analysed and suitably minimized. The results will contribute to the database for projects of combustion systems optimization, aiming to increase the efficiency and soot emissions control.
\end{abstract}

Keywords: Soot Emissions; Laminar Diffusion Flames; Commercial Fuels

\section{Introduction}

The aim of this work is the soot and radiation emission analysis in laminar diffusion flames produced by commercial gases distributed in Brazil to cook, Liquefied Petroleum Gas (LPG) and to automobile industry, Natural Gas Vehicle (NGV). Laminar diffusion flames of 80 $\mathrm{mm}$ visible height stabilized on a Burke-Schumann burner are considered, including using $\mathrm{CH}_{4}$ in order to validate the measurements.

The soot is an important participate media in the thermal radiation exhibiting a fundamental role in the heat transfer within combustion systems. Thus, the interest of measuring the soot emissions is given by the importance of the process of soot production in flames, which enables controlling the basic elements of hydrocarbon combustion [1].

The soot emission has been the focus of many studies due to applications in industry and also the prejudicial effects caused to the environment [2]. The presence of soot is of fundamental importance to the heat transfer in boilers and combustion chambers, contributing significantly to increased efficiency of these systems. In con- troversy, the inhaled soot may cause respiratory system damage and even cancer. Moreover, another important aspect is the contribution to the greenhouse effect. The atmospheric pollution is strongly associated with the industry and automotive soot emissions, contributing to considerable global warming [3]. In this way, many studies are being done in order to investigate the soot formation [4,5].

There are several techniques being able to measure the soot properties, each having specifics skills and limitations. In this work an experimental setup is built to implement the techniques, which use laser light extinction (EXT) to calibrating the results achieved and laser induced incandescence (LII) [6,7]. The LII technique measurements are desired because they provide high spatial resolution. These non-intrusive techniques provide instantaneous information in real time of local soot volume fraction and soot particle size employed in combustion $[8,9]$. The measurements are calibrated and validated by using methods and results available in the literature $[10,11]$.

The results could contribute to the basis for combustion systems optimization, aiming to assist projects in 
order to increase the energy efficiency and soot emissions control.

\section{Experimental Approach}

\subsection{Burner Configuration}

The study is performed in laminar diffusion flames using a burner of configuration proposed by Burke-Schumann [12], in which two concentric tubes are used, the internal one with $4.7 \mathrm{~mm}$ and the external with $45.0 \mathrm{~mm}$ of diameter, in order to guaranty an axisymmetric laminar flame. The internal tube is responsible to the fuel stream and the external by the air stream in coflow. Figure 1 shows the burner setup with components dimensions.

The volumetric flows are measured using a flowmeter to air (AppliTech), scaled of 15 - 160 slpm, 2\% of uncertainty, and also a flowmeter to fuel (ASA), ranging from 0.15 to $1.4 \mathrm{slpm}, 5 \%$ of uncertainty. The approximated flows and velocities yielded to the flames are shown in the Table 1.

\subsection{Flames Aboard}

The subject of this work is flames of $50 \mathrm{~mm}$ of visible height, as can seem in the Figure 2, considering $\mathrm{CH}_{4}$ or NGV or LPG as fuels. The volumetric flow of the fuels

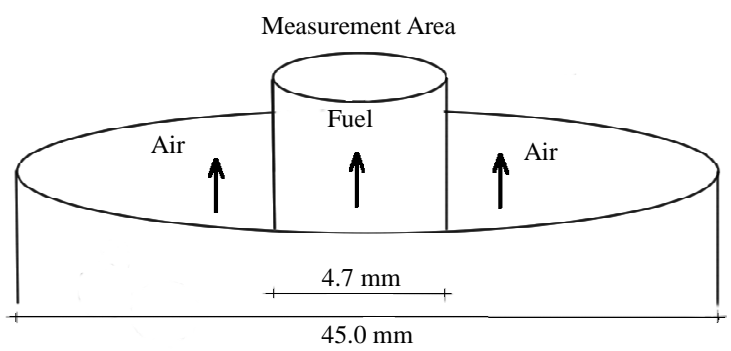

Figure 1. Burner schematic representation.

Table 1. Volumetric flows and flowfield velocities to the flames.

\begin{tabular}{ccccc}
\hline $\mathrm{h}(\mathrm{mm})$ & $\mathrm{V}_{\text {fuel }}(\mathrm{l} / \mathrm{min})$ & $\mathrm{V}_{\text {air }}(\mathrm{l} / \mathrm{min})$ & $\mathrm{U}_{\text {fuel }}(\mathrm{m} / \mathrm{s})$ & $\mathrm{U}_{\text {air }}(\mathrm{m} / \mathrm{s})$ \\
\hline 80 & 0.15 & 12.00 & 0.14 & 0.10 \\
\hline
\end{tabular}

and air are monitored, also the velocities of these flowfields, for each flame.

\subsection{Experimental Approach}

\subsubsection{Laser Light Extinction Technique}

The approach used for calibration is shown in the Figure 3. This setup is applied to perform the laser light extincttion technique, which consists to focus the laser beam in the flame and capture the light transmitted.

The extinction of the light, i.e., the difference between the intensity after and before the laser beam passes through the flame is proportional to the mean soot volume fraction in the line of sight. As proposed by the BeerLambert law applied to soot analysis [10]. The flame thickness is measured performing a digital image processing, counting pixels with calibrated dimensions at different flames heights. The extinction coefficient, 7.8, was taken from the literature [13] and compensated to the laser wavelength used in this work.

The results obtained from this application are mean and global, nevertheless, are usefulness to calibrate the qualitative results achieved by LII $[10,11]$, which provide spatial resolution. The illumination in the extinction technique system consists of a wave continuum Argon ion laser of $514.5 \mathrm{~nm}$ of wavelength and light power of $2 \mathrm{~W}$.

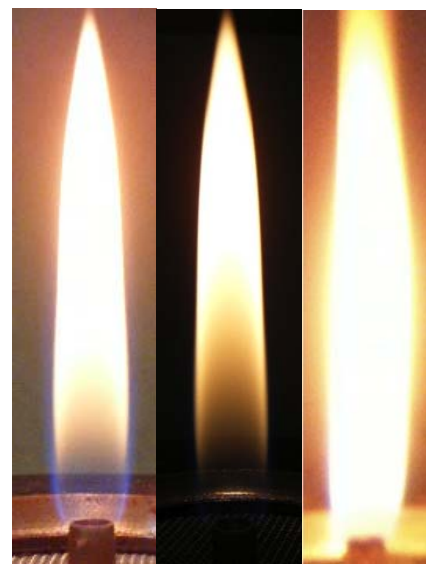

Figure 2. Flames visible height of $50 \mathrm{~mm}$, considering the fuels $\mathrm{CH}_{4}$, NGV and LPG, from left to right.

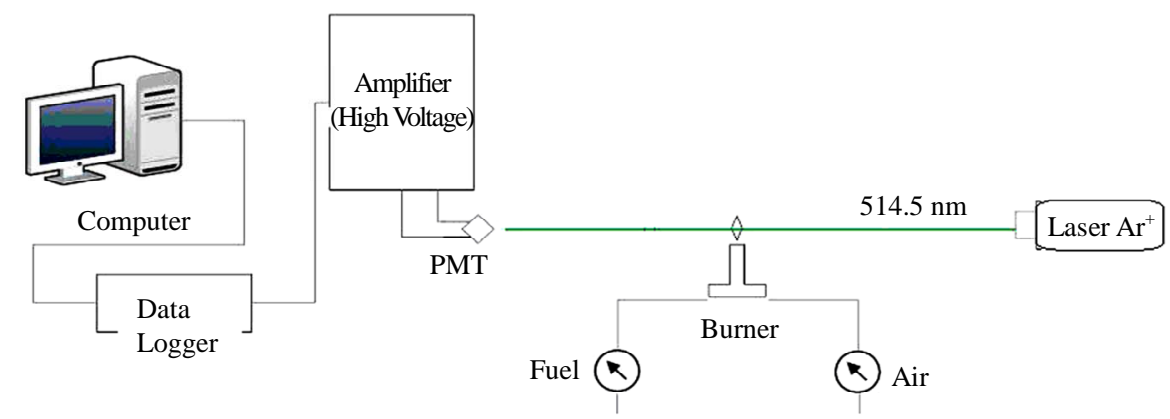

Figure 3. Scheme of laser light extinction experimental setup. 
The detection system is a photomultiplier tube (PMT), Hamamatsu, 931A. The measurements are taken spaced $10 \mathrm{~mm}$ in the longitudinal direction each other with cadence of $10 \mathrm{~Hz}$ during 60 seconds totalizing 600 samples in order to get statistical confidence.

\subsubsection{Laser Induced Incandescence Technique}

The results of soot volume fraction, $f_{v}$, obtained by LII measurements were taken using the assemblage shown in the Figure 4, as proposed by [6,7].

The produced information by this system is local, i.e., provide results about soot concentration of the flame presenting high spatial resolution, circa $0.5 \mathrm{~mm}$ in this work. For this measurements is require a pulsed laser Nd: YAG, New Wave, with $532 \mathrm{~nm}$ of wavelength and $33 \mathrm{~mJ}$ per pulse in a cadence of $30 \mathrm{~Hz}$ in order to induce the incandescence of soot when the beam is focus on a small volume in the flame, transmitting an energy of about 0.7 $\mathrm{J} / \mathrm{cm}^{2}$. This signal of incandescence is captured by the PMT aided by a band-pass filter, which is centered in $650 \mathrm{~nm}$, used to avoid the noise of the flame and background. The incandescence signal intensity is measured using an oscilloscope Tektronics, TDS 210, coupled in a computer.

\subsection{Measurements Uncertainty}

In the development of the experiments were found many difficulties that could yield low accuracy to the measurements. However, possible solutions were proposed to each problem. The flame instability causes by the flow controller absence affected on the signal detected. The light emitted by the flame alters the intensity of light captured by the sensors and also the flame oscillations at the top position changes the LII measurements results. Thus, was used a band-pass filter for increasing the signal to noise ratio. Nevertheless, the signal intensity belong small become difficult the measurements of low values in regions where small $f_{v}$ are present, as found in the flame basis.

The laser power supply varies producing intensity variations. In order to avoid this problem a largeintegration time was used to take the signals. Also, the pres-

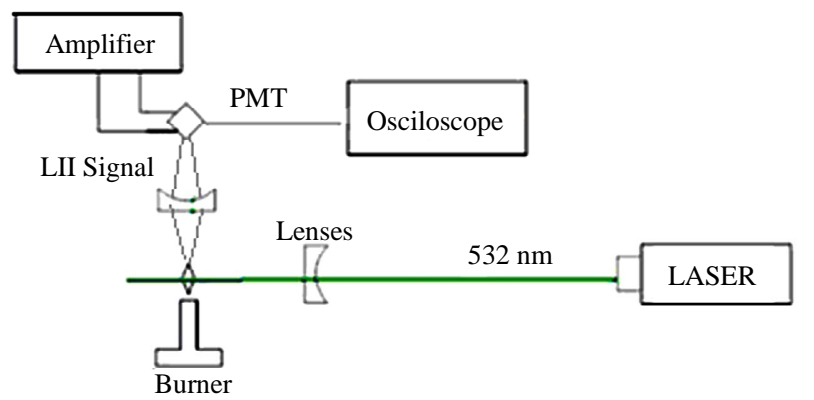

Figure 4. Scheme of laser induced incandescence setup. ence of dust in the laboratory and the soot accumulation in the room along the experimental time are important factors to increase the uncertainty.

The uncertainty in soot volume fraction measurements involves the following components as source to the laser light extinction technique, 1) laser light intensity, $\pm 6 \%$; 2) soot extinction coefficient, $\pm 8 \%$; 3 ) laser light wavelength, $\pm 2 \%$; 4) flame thickness, $\pm 1.5 \%$. Thus, the total uncertainty in light extinction measurements is obtained by the propagation yielding circa $\pm 10.5 \%$.

The measurement uncertainty in LII is estimated using the relative deviation from the results achieved by laser light extinction, which provide quantitative global values of $f_{v}$. Toward determine this uncertainty was considered the methane flame, taken in account the discrepancy, which was estimated as roughly $\pm 6 \%$.

\section{Results and Discussion}

\subsection{Measurements Validation}

The results achieved to the methane flames are compared with the literature [9], in order to validate the measurements for different fuels, NGV and LPG, are shown in the following graph. The results present the soot volume fraction, $f_{v}$, on each $10 \mathrm{~mm}$ height, $h$, at the longitudinal direction of the flame.

The results of this work have shown in agreement with the literature, circa $\pm 20 \%$ of maximum discrepancy, as illustrate in the Figure 5.

\subsection{Experimental Results}

The mean results obtained using light extinction (EXT) and LII for different fuels are shown in the Figure 6. The values of $f_{v}$ for LPG are higher for both cases and the $\mathrm{CH}_{4}$ are generally $50 \%$ smaller. The NGV exhibits roughly $20 \%$ less soot compared with LPG.

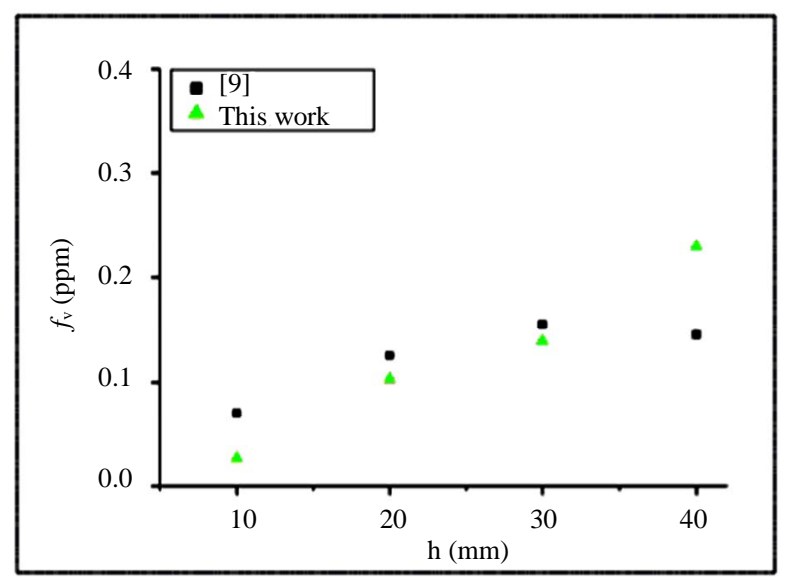

Figure 5. Comparison between the results obtained in this work with the literature in order to validate the measurements. 


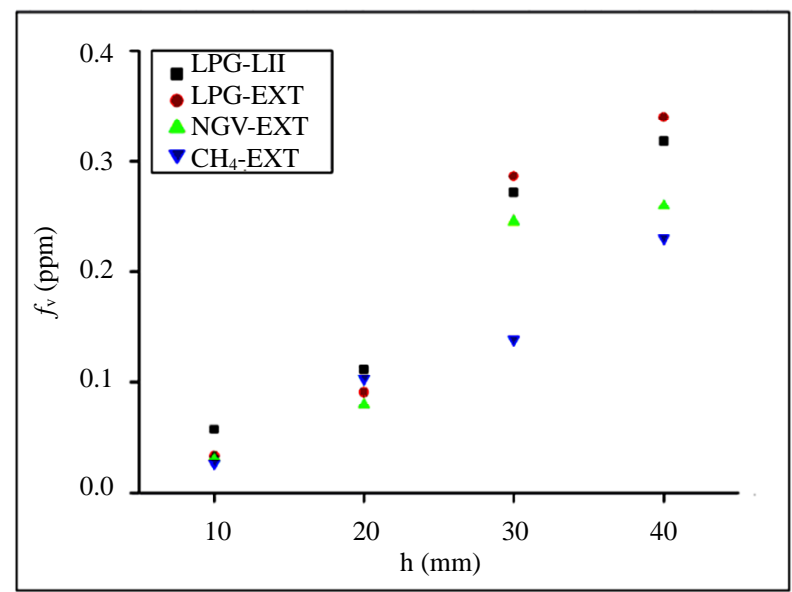

Figure 6. Results of $f_{\mathrm{v}}$ to the laminar flames produced by LPG, NGV and $\mathrm{CH}_{4}$.

In the Figure 6 the black squares presents the $f_{v}$ values to LGP fuel flame, captured by LII technique, along the longitudinal direction upward the burner surface. The red circles indicate the $f_{v}$ results to LGP from light extinction measures, which were taken in order to calibrate the LII results. The green and blue triangles are the $f_{v}$ values achieved from light extinction technique to $\mathrm{CH}_{4}$ and NGV fuels, respectively.

To measure in the extremities of the flame was found some difficulties, both top and bottom, due the instability at the top region of the flame and, also, the low values of soot volume fraction in the bottom region. The behaviour of the values agrees with published by [11]. The precursor of the soot is formed in the flame base by the excess of fuel and reaches the maximum concentration at the medium where the high temperature starts the oxidation the aggregates and the soot concentration decreases.

The results of $f_{v}$ just above the burner, around $10 \mathrm{~mm}$, where the precursors of soot are formed, exhibits very low values, around $0.01 \mathrm{ppm}$ or $10 \mathrm{ppb}$, so that it is difficult to measure accurately. In the other hand, the maximum values of $f_{v}$ are found in the range from 30 to 40 $\mathrm{mm}$ in the longitudinal positions, presenting values about $0.3 \mathrm{ppm}$. Whereas, downstream this region is noted a smooth decrease of the $f_{v}$ values, between 40 and $50 \mathrm{~mm}$, circa 0.2. This behaviour is due the oxidation of the agglomerates, as described by literature [11].

The behaviour of the results obtained using LII in the LGP flame measurements agree with those from light extinction, including to the all of fuels studied in this work. However, the LPG fuel shown higher values of $f_{v}$, followed by $\mathrm{NGV}$ and $\mathrm{CH}_{4}$. It was expected, considering the carbon number in the chemical structure, that the sequence LPG, NGV and $\mathrm{CH}_{4}$, respectively, presents the higher to low soot emissions due the same combustion conditions, i.e., in a laminar diffusion flame, in which the carbon content into the fuel requires to diffuse an oxygen from the surrounding air to reaction occurs. This happens because the LPG is formed by propene and butane $\left(\mathrm{C}_{3} \mathrm{H}_{8}\right.$, $\mathrm{C}_{4} \mathrm{H}_{10}$ ), while NGV is composed by approximately $80 \%$ of $\mathrm{CH}_{4}$ and $20 \%$ of other hydrocarbons like ethane $\left(\mathrm{C}_{2} \mathrm{H}_{6}\right)$, propane and butane.

\subsection{Signal Processing}

Furthermore, the LII technique was used to take local measures with enough spatial resolution in order to create transversal profiles at each longitudinal measurement height. Thus, the fit between $f_{v}$ values measured by both techniques are in agreement, $5 \%$ maximum discrepancy, regarding the measurement uncertainty attributed to this technique and the level of correlation. Thus, these results corroborates to the validity of the behaviour achieved globally by the light extinction and, locally, with LII measurements.

\section{Conclusions}

Techniques used to determine the soot volume fraction presented coherent results compared with the literature, values and relation.

Thus, the total uncertainty in light extinction measurements is obtained yielding circa $\pm 10.5 \%$. The measurement uncertainty in LII is estimated as roughly $\pm 6 \%$. The difficulties and uncertainty sources can be minimized by using optical filters, stable supplies and flow controllers.

The behaviour of the LII data related to $f_{v}$ as function of the flame height fitted with results of extinction results. The compatibility between these methods was observed, allowing performing global measurements with light extinction, leading to use LII to obtain spatial resolution and particle diameter results, from other fuels, in future works.

Experimental results showed, as expected considering the number of carbon in the chemical structure, that the LPG has the higher $f_{v}$ values, followed by NGV and $\mathrm{CH}_{4}$, respectively, i.e., the higher to smaller soot emissions produced by the commercial fuels. The values of $f_{v}$ for LPG are higher because both cases and the $\mathrm{CH}_{4}$ are generally $50 \%$ smaller. The NGV exhibits roughly $20 \%$ less soot compared with LPG. The behaviour of the results obtained by using LII flame measurements agrees with light extinction.

\section{Acknowledgements}

Authors want to thank the financial support of CNPq Brazilian agency fostering research.

\section{REFERENCES}

[1] R. T. Wainner and J. M. Seitzman, "Soot Diagnostics 
using LII in Flames and Exhaust Flows,” American Institute of Aeronautics and Astronautics, 1999.

[2] P. O. Witze, S. A. Shimpi, R. P. Durrett and L. A. Farrell, "Time-Resolved Laser-Induced Incandescence Measurements for the EPA Heavy-Duty Federal Test Procedure," JSME International Journal, Series B: Fluids and Thermal Engineering, Vol. 48, No. 4, 2005, pp. 632-638.

[3] E. Geraque, "Fuligem Corresponde Por Terco do Aquecimento Global,” Folha de São Paulo, 2009.

[4] A. Boiarciuc, F. Foucher, B. Moreau, O. Pajot and C. Mounaïm-Rousselle, "Simultaneous Spatial and Temporal Resolved Laser-Induced Incandescence to Study the Soot Particles Formation,” Ph.D. Thesis, University of Orléans, Orléans, 2004.

[5] L. G. Barreta and M. E. Sbampato, "Imaging of Laser-Induced Fluorescence in an Ethanol Atmospheric Flame,” 30th Encontro Nacional de Física da Matéria Condensada, 2007.

[6] A. C. Eckbreth, "Effects of Laser-Modulated Particulate Incandescence on Raman Scattering Diagnostics," Journal of Applied Physics, Vol. 48, No. 11, 1977 pp. 44734483. http://dx.doi.org/10.1063/1.323458

[7] L. A. Melton, "Soot Diagnostics Based on Laser Heating,” Applied Optics, Vol. 23, No. 13, 1984, p. 2201. http://dx.doi.org/10.1364/AO.23.002201

[8] R. L. Vander Wal and K. J. Weiland, "Laser-Induced Incandescence: Development and Characterization to- wards a Measurement of Soot-Volume Fraction,” Applied Physics, Vol. 59, No. 4, 1994, pp. 445-452.

[9] R. L. Vander Wal, T. M. Ticich and B. Stephens, "Can Soot Primary Particle Size Be Determined Using LaserInduced Incandescence?” Combustion and Flame, Vol. 116, No. 1-2, 1999, pp. 291-296. http://dx.doi.org/10.1016/S0010-2180(98)00040-6

[10] M. Y. Choi, G. W. Mulholland, A. Hamins and T. Kashiwagi, "Comparison of the Soot Volume Fraction using Gravimetric and Light Extinction Techniques,” Combustion and Flame, Vol. 102, No. 1-2, 1995, pp. 161-169. http://dx.doi.org/10.1016/0010-2180(94)00282-W

[11] C. Shaddix, "Laser-Induced Incandescence Measurements of Soot Production in Steady and Flickering Methane, Propane, and Ethylene Diffusion Flames,” Combustion and Flame, Vol. 107, No. 4, 1996, pp. 418-452. http://dx.doi.org/10.1016/S0010-2180(96)00107-1

[12] S. P. Burke and T. E. W. Schumann, "Diffusion Flames," Combustion Symposium, Vol. 20, 1928, pp. 998-1004.

[13] T. C. Willians, C. R. Shaddix, K. A. Jensen and J. M. SuoAnttila, "Measurement of the Dimensionless Extinction Coefficient of Soot within Laminar Diffusion Flames," International Journal of Heat and Mass Transfer, Vol. 50, No. 7-8, 2007, pp. 1616-1630. http://dx.doi.org/10.1016/j.ijheatmasstransfer.2006.08.02 $\underline{4}$ 